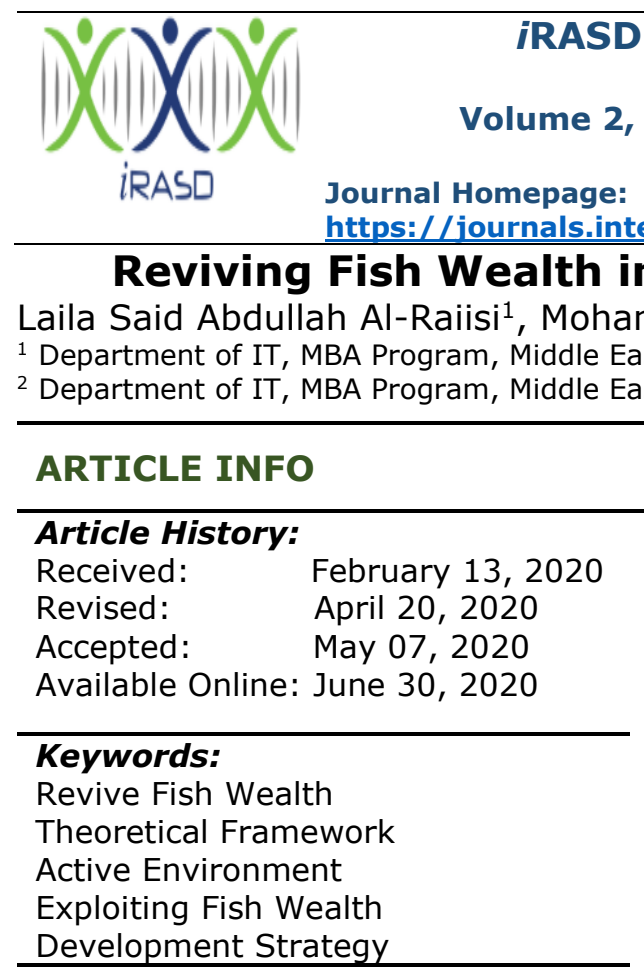

Journal of Management

(n)

https://journals.internationalrasd.org/index.php/jom

Laila Said Abdullah Al-Raiisi ${ }^{1}$, Mohammad Saqib ${ }^{2}$

${ }^{1}$ Department of IT, MBA Program, Middle East College, Muscat, Sultanate of Oman, Email: Pg18f1940@mec.edu.om

\title{
ABSTRACT
}

This electronic paper looks to revive fish wealth through underwater technology in finding a suitable and efficient way of fishing and marine wealth, which involves a feasibility study after critical thinking, research interview methodology and shows research purpose. This paper also includes a theoretical framework based on the literature review and critical analysis of strategic decision-making models that may impact fisheries strategies. A development strategy is the ability to understand the nature of the problem and then evaluate it by analyzing and identifying the planned solutions as an active environment. Ultimately, in designing an adequate and efficient underwater technology system for exploiting fish wealth in Oman, I will provide living examples of best practices in the world about this aspect. There are some potential approaches and how to handle the future of fisheries.

(C) 2020 The Authors, Published by iRASD. This is an Open Access article under the Creative Common Attribution Non-Commercial 4.0

\section{Corresponding Author's Email: Pg18f1940@mec.edu.om}

\section{Introduction}

The Ministry of Agriculture and Fisheries (MAF) of Oman works in agriculture, livestock, and fisheries. It has laws, regulations, and decisions (Jones, 2020). The Ministry's vision is looking for a sustainable strategy for the future (2020, السمكية).

This research touches on the importance of underwater intervention in fishing because its economy must be diversified and depend on oil and gas wealth. Besides, the Omani coast's length is 3,165 KM square, and Oman has located on the Arabian Gulf, the Gulf of Oman, and the Arabian Sea. The geographical location made it an environment rich in fish wealth and abundant in different types of fish (Alhabsi, 2012). Therefore, that motivated me to search for the extent of technological progress as underwater intervention (UI), which is not available in Oman's MAF.

\subsection{Problem Specification}

\section{A. Challenges Of New Fishing Methods}

There is rapid progress in modern technology and development around the world. Therefore, Underwater technology must be concerned. The most important challenges

The Ministry of Agriculture and Fisheries (MAF) of Oman.

The task is to use technology innovation in a suitable marine environment in Oman to support fishing and society's job opportunities by enhancing their services to the desired level (Maas, 2015).

Five challenges for UI implementation must be considered as follows:

i. Risk mitigation for remoting the operation.

ii. Complex to manage. 


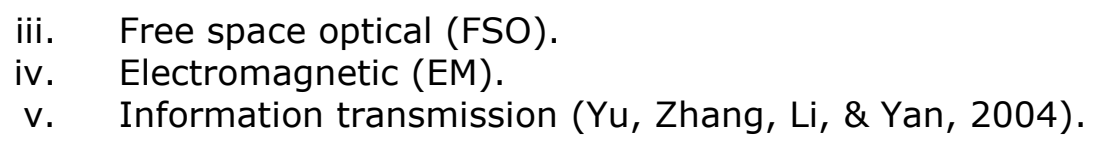

\section{B. Lack Of Care \& Consideration}

Limited companies developed underwater technology and dominated the market at constant prices and high costs. It is considered a complex technology due to the lack of efficient aquatic information collecting, visual survey, and essential planning data (Yu et al., 2004).

\subsection{Objective of research}

Fish wealth is rich in increasing the national economy, trade boom, employment opportunities, rural development, and food security for the present and future (FAOUN, 2020). Besides, its good alternative income besides oil and gas (Yu et al., 2004).

The objectives of the research set out as follows:

i. Study the current strategies of fisheries in Oman.

ii. A critical study of Underwater Intervention.

iii. Select and analyze the technological fishing intervention in different countries.

iv. Evaluate the performance \& qualitative factor of Underwater Technology.

v. How to overcome challenges with a successful outcome.

Ultimately feed my suggestions and recommendations as a development strategy for the best integration of fishing underwater technology besides manual fishing tools also how it causes a strong impact in the fisheries sector (Gibbs \& Thébaud, 2012).

\subsection{Research questions}

The main research questions under review have been as follows:

A. What are the requirements for choosing and assessing methods of fishing?

B. How to measure fishing methods ' quality and efficiency?

C. What has been the improvement of IT strategy to impact fishing? (Example feed the answer)

\section{4. theoretical framework}

Fish groups are divided into three main groups:

i. Surface fish.

ii. Benthic fish.

iii. Crustaceans and mollusks.

Which is located in the Sultanate of Oman and the fishermen catching with fishing equipment (2020, السمكية) that divided into three types:

i. Nets.

ii. Cages.

iii. Strings.

The criteria should be determined of the best option for fishing by studying and analyzing through deciding with a qualified team in the Ministry of Agriculture and Fisheries of Oman. They should take the time to think in-depth about the advanced technology in fishing and the existence of previous traditional methods (Berg, 2018). 
The process of fishing goes through these phases, as shown below in figure1:

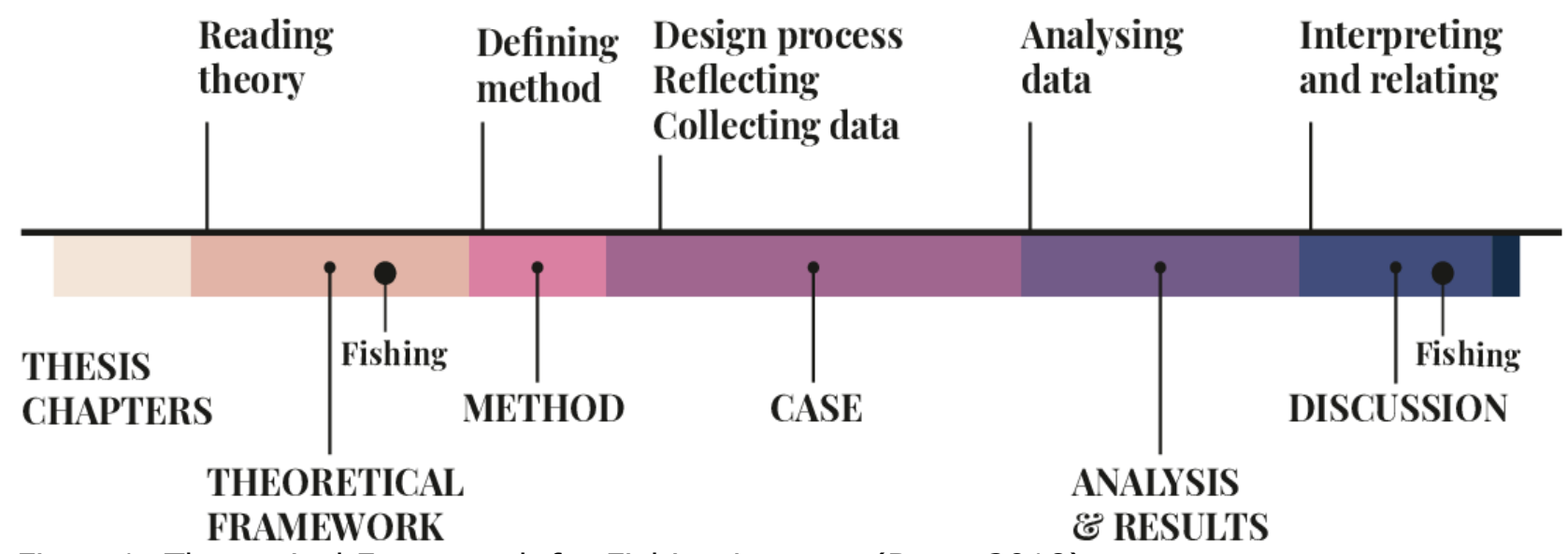

Figure1: Theoretical Framework for Fishing Lessons (Berg, 2018).

\section{2. literature review}

After reading several scholarly articles, it deals with much information. The paper is organized as follows:

Fishermen land their catch using a wide range of gear. That type has its oceanic impact. The fishing industry can help minimize its effect on the environment by choosing the right person for the right job (Methods, 2020). There is much gear to select as follows:

i. Beach and boat seines.

ii. Bottom Trawls.

iii. Dredges and Gillnet.

iv. Handlines and Jigs.

v. Harpoons and long lines.

vi. Midwater trawls.

vii. Pole and line.

viii. Trolling lines.

ix. Pots and purse seines.

The majority of the fish we eat in the next decade will be farmed, not wild. Over 100 species of global aquaculture are cultivated from traditional earthen ponds to high-tech tank systems. Consumers can positively reduce the potential adverse impacts of aquaculture (Methods, 2020).

Underwater Technology is a technology of ocean science and offshore engineering. Many societies around the world are interested in underwater intervention (Gibbs \& Thébaud, 2012).

Underwater engineering, the role of remotely operated vehicles (ROVs) is reviewed an important because of the auto-multi-task system, especially with the operation of fisheries as follows: fish search, detection, capture, storage, and transport with efficiency and integration within short (time \& effort) and higher incomes (Vanhée, Borit, \& Santos, 2018). Future expectations that the offshore industry will be the primary market in the short term (SUT, 2020). With the vital technical problems identified as structure inspection and underwater welding, the leading offshore activities for which vehicles can be used are considered. Also, possible vehicle design changes are addressed to improve performance and handling, and the value of exemplary man-machine interfaces is stressed (SUT, 2020).

Many international companies propose underwater technology to gain global market share and lead to ocean resources' sustainable use. An example of that: GCE Ocean Technology international of the Norwegian subsea cluster (GCE, 2020). MacArtney Group is a global worldwide, but MacArtney Headquarters in Denmark (Technology, 2020). It is responsible for a supplier of underwater technology specialization in design \& manufacture (Technology, 2020). 
By receiving and responding quickly to many and more demands. Think of the new technologies and the inflation that has happened now a day. Both agencies and organizations are, therefore, switching to the offshore industry.

Many international companies are moving to underwater technology because of providing new service and an excellent choice to enter a new market. The challenges that may face difficulty managing are deeper water, more complicated logistics, navigation, and Independent adaptation to autonomous changes (Patrón \& Petillot, 2008).

\section{Methodology}

\section{Interview Method in the research}

An interview was conducted with Mr. Khalid Mohammed Abdullah Al Balushi, Director of the Central Wholesale Fish Market in Barka. As I mentioned before, the talk included the main research questions, $A, B$, and $C$, as above.

The questions are made up of three items that allowed the participant to express their views. To ensure that the responses were reliable, the data we obtained was checked through research and the Ministry's website.

\subsection{The Current Research Study}

This research explained and justified the need to analyze the problem specification, as mentioned above. Also, the fishing methods do not have technological intervention in Oman. Identify the effect of a development design resulting from successful underwater technology (innovation). Then, determine the indicator of success and how it impacts to complete the five primary fishing operation process through autonomous as shown below in the figure the technology options and comparison table between manual fishing tools and fishing underwater technology after underwater technology exceeds the barriers achieves the goals while implemented. The planning process for design and development needs to expand and spread across the world in general (2020, العمانية).

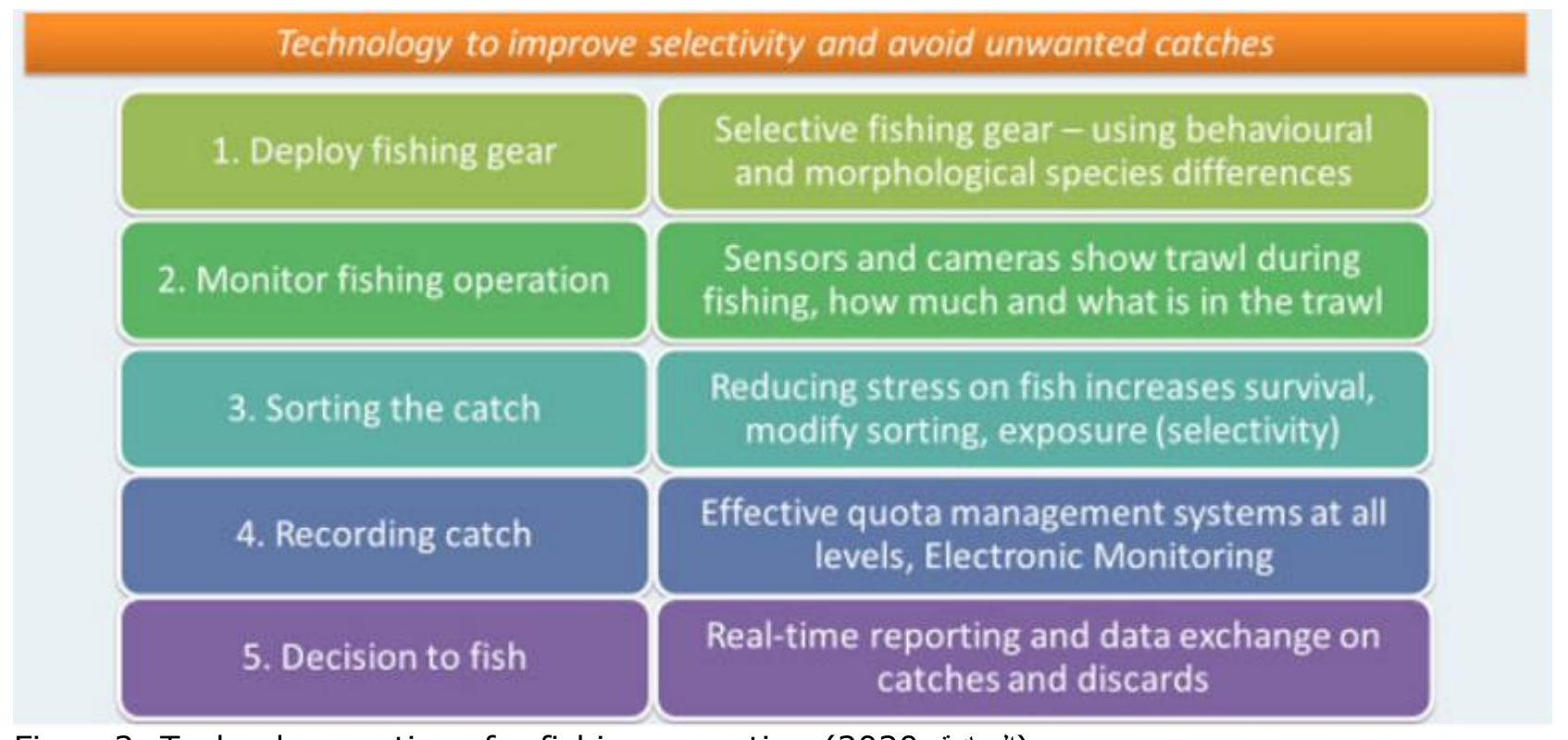

Figure2: Technology options for fishing operation (2020, العمانية) 
Table1

Development Strategy Analysis

\begin{tabular}{|c|c|c|}
\hline Attributes & Fishing Methods & \\
\hline Identify & $\begin{array}{l}\text { Underwater technology (autonomous (Paul, } \\
\text { 2020)) }\end{array}$ & $\begin{array}{l}\text { Methods used in Oman } \\
\text { (net, string, cage) }\end{array}$ \\
\hline Performance & $\begin{array}{l}\text { High quality \& ethical treatment (Paul, 2020) } \\
\text { short time \& less effort }\end{array}$ & Fishers effort more need time \\
\hline Amount of production & Greater & Less \\
\hline Operation & $\begin{array}{l}\text { Multi-tasks : search, detect,capture,storage } \\
\text { \& transport (Vanhée et al., 2018) }\end{array}$ & Capture \& storage \\
\hline Water pollution & friendly environmentally & May cause accident \\
\hline Cost & expensive & Cheaper \\
\hline Availability & limited & Available \\
\hline
\end{tabular}

The expectation barriers to the implementation of fishing underwater technology as follows:

It is costly because it is considered new technology and supplied by limited companies worldwide (Brooks, 2019). Challenges and complex configuration for imaging system installed on autonomous underwater technology. Losses acts of fishing gear and fishers skills (Matthew \& Cory, 2020). The system and application of electrical, visual, acoustic, and chemical may negatively impact marine life (Matthew \& Cory, 2020).

\section{Finding}

The Ministry of Agriculture and fisheries conduct education campaigns to define methods and tools (nets, cages, and strings) for fish stock evaluation, provide advice on fisheries, selection criteria, and guidelines for co-management of harvest reserves in the sea.

The measure fishing must present a robustness analysis method and the ability to adapt to appropriate procedures. Also, each fishing method has measurable fish-capture efficiency with which it was taken because of differences in size, quality, and species-establishing strict laws and penalties against poaching.

Finally, technology and progress in the Ministry's IT strategy have yielded a positive result due to high annual statistics. Over the past few years, the fisheries sector in the Sultanate of Oman has achieved high growth rates. According to statistical data, the total fish production of the Sultanate for 2018 amounted to approximately 553 thousand tones, up from $59 \%$ in 2017 with a total value of around 269,126 million riyals (2020, بنسبة). In 2019 amounted to about 580 thousand tons, up to $5 \%$ from 2018 , as shown below. A special commission for this research is dedicating a significant body of research and development. Since then, there has been a considerable effort to find appropriate solutions to some of the issues we faced. For example, better management of fish stocks and combating Illegal, unreported, and unregulated (IUU) fishing. Also, the way vessel control was easily tracked by satellite systems has changed significantly. (Remote Sensing). Besides, using a bathymetric survey to study bathymetry (depth measurement) as primary and accurate information. 


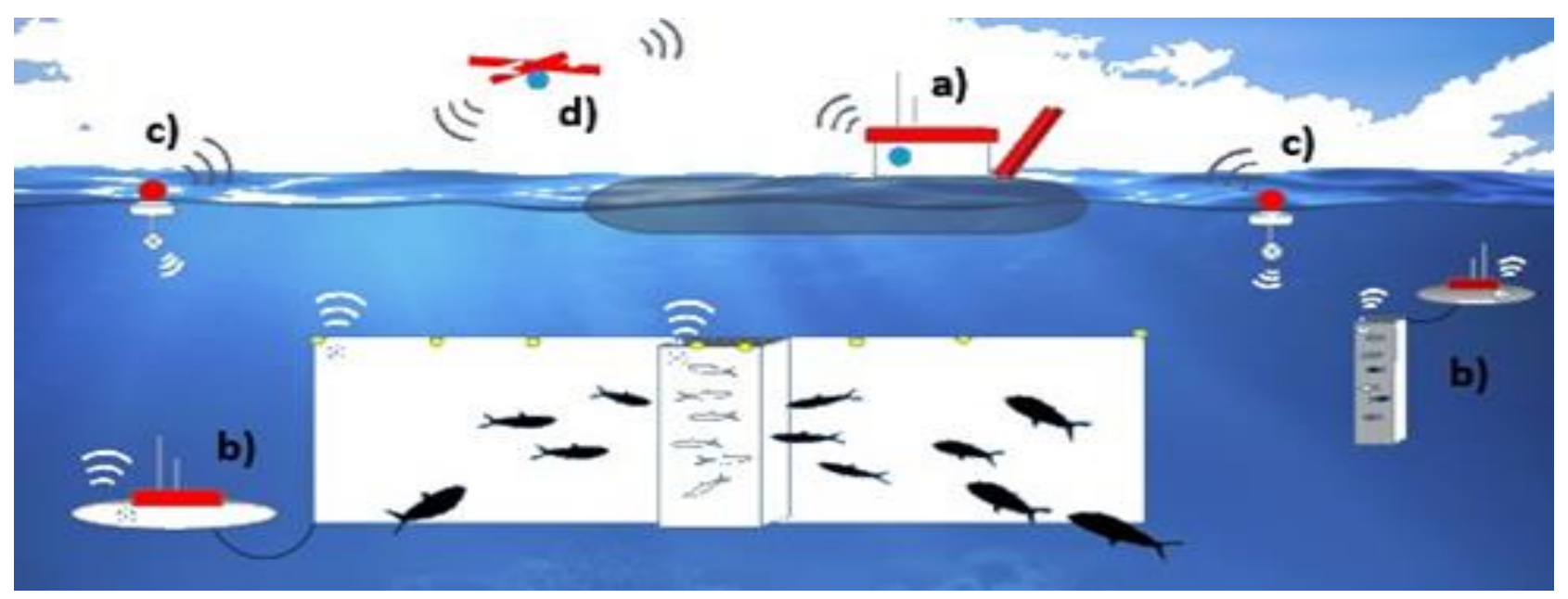

Table2

Fish Production for 2017, 2018 and 2019 (2020, بنسبة)

\begin{tabular}{lll}
\hline Year & Total fish production RO & Amount/tones \\
\hline 2017 & RO 183,963 million & 247,818 \\
2018 & RO 269,126 million & 553000 \\
2019 & RO 306,000 million & 580000 \\
\hline
\end{tabular}

\subsection{Best practice}

Besides the usual fishing methods mentioned previously, there are new and innovative technological methods in the world that have been discovered by Underwater Intervention Communities from different countries around the world.

Underwater Technology is a new market for companies. A future view of our phases is composed of a fishing operation through underwater intervention UI machines that completed the fishing operation by five main auto-processes, as I mentioned in the previous step (Literature Review). Examples were chosen Stø Technology (Paul, 2020) and Autonomous Fishing Operation System(AFOS) as a support vehicle (Vanhée et al., 2018), as shown below, Figures 2 \& 3. Explained the functions of both machines in Table3:

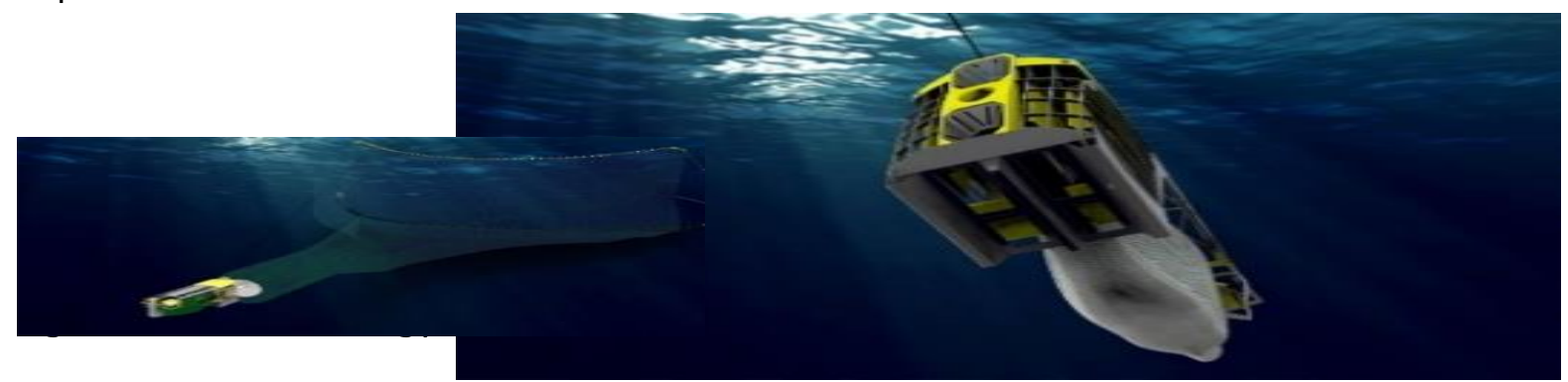

Figure 3: Autonomous Fishing Operation System(AFOS) (Vanhée et al., 2018)

Both have performance standards but with varying effectiveness. This cannot be measured because it is one of the innovations (Girard \& Du Payrat, 2017). 


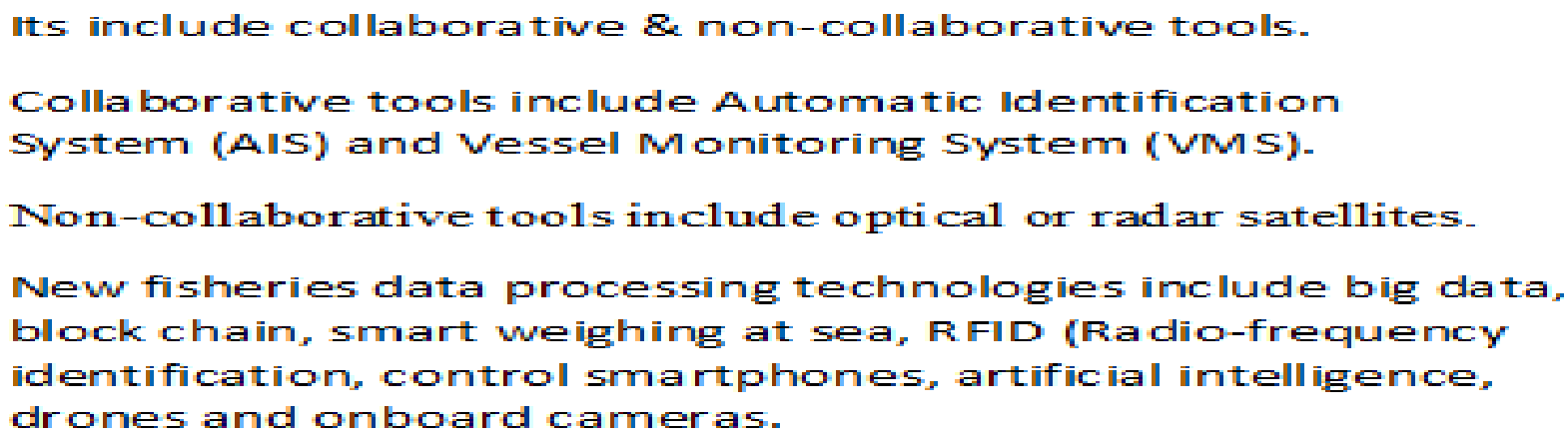

\subsection{Evaluation of (MAF) IT Strategy}

The Ministry of Agriculture and Fisheries of Oman (MAF) presented their IT strategy through optimizing the resources available in the fisheries sector in creative methods, tasks, and services to ensure their sustainability in the present and future with a distinct and high efficiency in achieving the Sultanate's food security(Jones, 2020). They have defined the IT Strategy that enabled them to find a proper way that is implemented as follows:

Remote Sensing is a practical application to monitor necessary changes in ecosystems and collects essential information about natural resources. A service for electronic fish licenses, approximately 24 services were launched through the website. They are using a bathymetric survey to study the depth of the sea with accurate measurement. New Center for quality control of fish equipped with the latest technology.

Strategy for the development of the fisheries sector 2020-2040. The criteria of a roadmap for advancing the fisheries sector have been drawn up and through which several laws, policies, and latest technology to implement.

There are four main objectives is concerned as follows (2020, العمانية):

i. The productivity of the fishing fleet.

ii. Development of infrastructure.

iii. Development of value-added fish sectors.

iv. Development of fish farming activities due to modern technology to increase production(2020, العمانية).

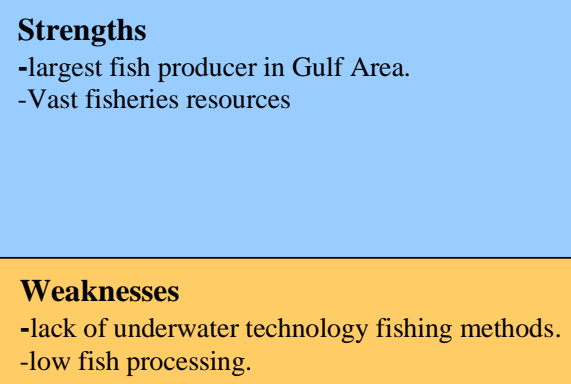

Figure 4: Swot analysis for IT Strategy

They are developing a five-year plan for fisheries extension in Oman. The management in the decision-making strategy to move toward service-led growth in the Ministry of Agriculture and Fisheries of Oman (Jones, 2020). The pros of IT strategy to adopt a more systematic 
hypothesis testing strategy and faster decision-making. For example, any decision-making and planning about the sea depth required a series \& necessary information where bathymetry is a significant part.

\section{5. recommendation \& conclusion}

According to the literature review's positive measurement and current research study outlines, as shown in previous phases. I recommend adding underwater technology besides manual \& traditional methods for improving speed, productivity, and relationship quality results in fishing through the proper way as a friendly environment. Besides ethical treatment, the fish can get by the best use of raw material and value creation. Underwater Technology may effect on reviving fish resources in Oman for sustainable fisheries business development to make an essential contribution to the national economy by increasing the annual production and food security for future generations.

\section{References}

Alhabsi, M. S. (2012). The fisheries community of Albatinah region in Oman: a socio-economic overview. J. Fish. Sci. com, 6(3), 215-223.

Berg, E. (2018). Fishing lessons-Capabilities approach in the design process for public work and daytime activity services for disabled people.

Brooks, M. E. (2019). ICES-FAO Working Group on Fishing Technology and Fish Behaviour. ICES report.

FAOUN. (2020). The Sultanate of Oman. Retrieved from http://www.fao.org/fishery/facp/OMN/en

GCE. (2020). GCE Ocean Technology. Retrieved from https://www.bluetechclusters.org/wwwgceoceanno

Gibbs, M. T., \& Thébaud, O. (2012). Beyond individual transferrable quotas: methodologies for integrating ecosystem impacts of fishing into fisheries catch rights. Fish and Fisheries, 13(4), 434-449.

Girard, P., \& Du Payrat, T. (2017). An inventory of new technologies in fisheries. Paper presented at the The Green Growth and Sustainable Development (GGSD) Forum.

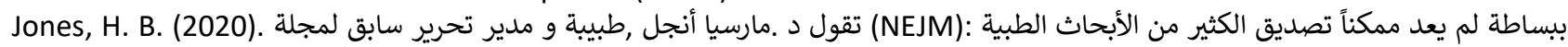

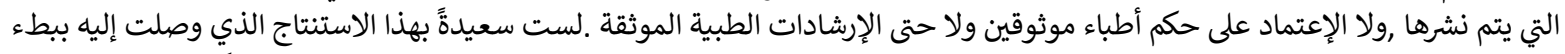

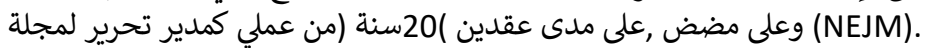

Maas, D. (2015). Best fishing innovations. Retrieved from https://www.bassmaster.com/gear/top-5-fishing-innovations

Matthew, R. N., \& Cory, D. S. (2020). Non-Physical Barriers To Deter Fish Movements - Environmental Reviews. Retrieved from https://www.nrcresearchpress.com/doi/10.1139/a2012-001\#.XhcF225uLHo

Methods, F. F. (2020). Fishing And Farming Methods From The Seafood Watch Program At The Monterey Bay Aquarium. Retrieved from https://www.seafoodwatch.org/ocean-issues/fishing-and-farming-methods

Patrón, P., \& Petillot, Y. (2008). The underwater environment: A challenge for planning. UK PlanSIG Edinburgh.

Paul. (2020). Nor-FishingThe industry's meeting place. Nor-FishingThe industry's meeting place. Retrieved from https://www.nor-fishing.no/nominated-to-the-innovation-award-sto-technology

SUT. (2020). Oceans of Opportunity The Underwater World of Science and Technology. Retrieved from https://www.sut.org/event/oceans-of-opportunity-the-underwater-world-of-science-and-technology/

Technology, M. U. (2020). Who We Are. Retrieved from https://www.macartney.com/who-we-are

Vanhée, L., Borit, M., \& Santos, J. (2018). Autonomous fishing vessels roving the seas: what multiagent systems have got to do with it.

Yu, J., Zhang, A., Li, Z., \& Yan, K. (2004). The development and the challenges of underwater vehicles for polar expedition. Paper presented at the Proceedings of the 2004 International Symposium on Underwater Technology (IEEE Cat. No. 04EX869).

12020. (I, السمكية. Ministry of Agricultural, Fisheries and Water Resources - Sultanate of Oman. Retrieved from https://www.maf.gov.om/Fisheries

العمانية رج) Retrieved from

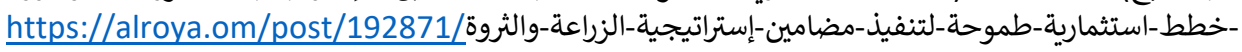

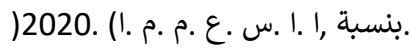

